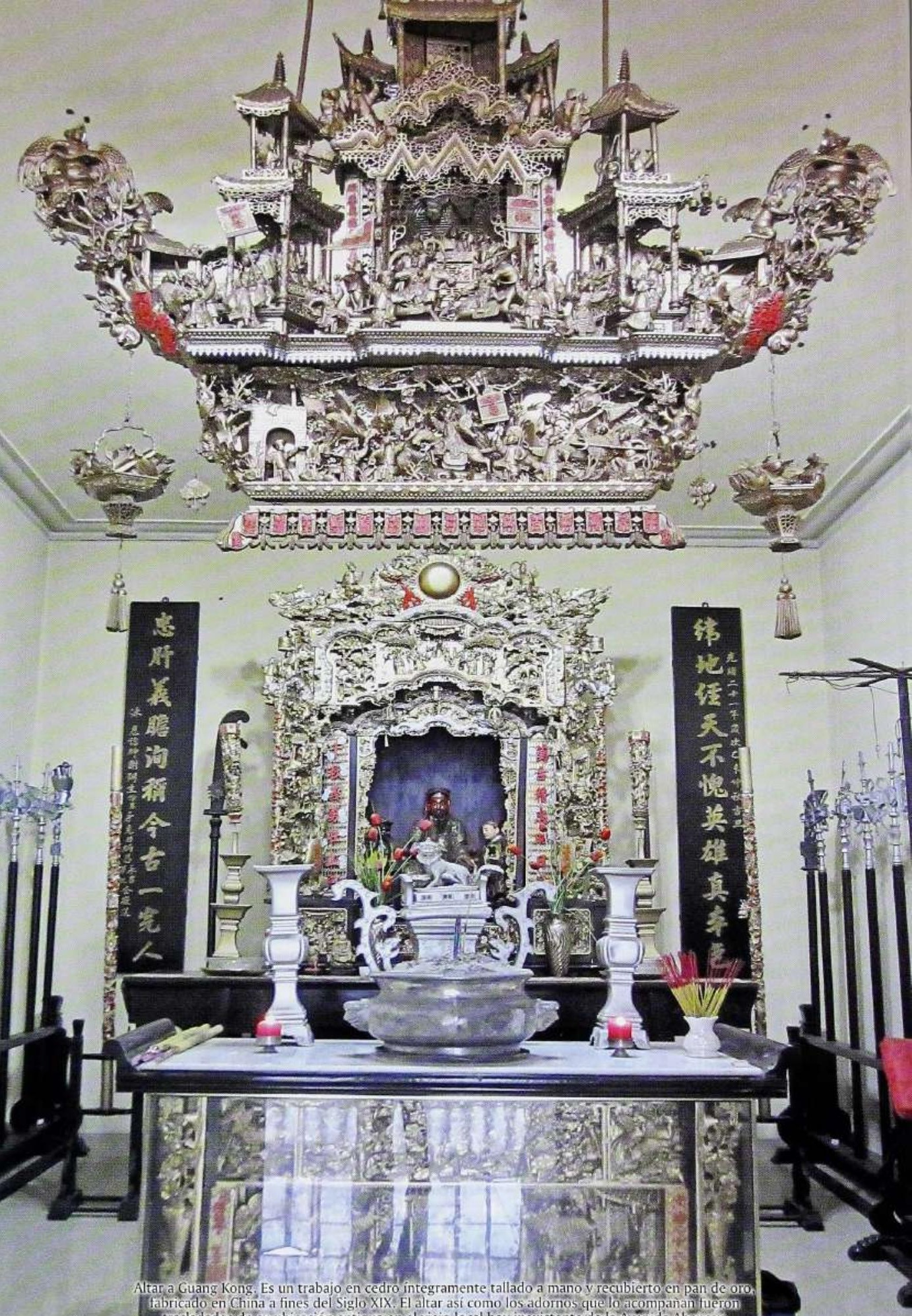




\title{
El Museo de la Sociedad Pun Yui del Perú
}

\author{
Richard Chuhue Huamán / Jessica Li Wong \\ Comité Peruano de Ciencias Históricas \\ Universidad Nacional Mayor de San Marcos
}

La Sociedad Pun Yui del Perú es una de las pocas sociedades formadas por inmigrantes chinos que en la actualidad posee un museo en el cual recoge las reliquias e historia de su institución. Dicho Museo fue ideado por la directiva hace unos años como una forma de rescatar y revalorar su patrimonio y evitar la pérdida del mismo, como lamentablemente ha ocurrido en otras instituciones similares en el país. En la actualidad el museo busca un acercamiento más directo con la sociedad, siendo el único en su tipo en el Barrio Chino de Lima.

Historia / Inmigración china / Lima / Patrimonio

The Pun Yui Society in Peru is one of the few societies formed by Chinese immigrants. They now have a museum with the relics and history of their institution. This museum was conceived by the board a few years ago as a way to rescue and revalue their heritage and avoid its loss, as it has unfortunately happened with similar institutions in the country. Nowadays, the museum seeks a more direct approach to society. It is one of a kind in Lima's Chinatown.

History / Chinese inmigration / Lima / Heritage

\section{Una Introducción a la historia de la región de Pun Yui en Cantón}

China (Zhōng Guó, 中国) es un país que posee 9897961 Kilómetros de vasto territorio y que actualmente se encuentra dividido en 23 provincias. Históricamente la migración de personas desde el Imperio Celestial hacia el Perú -proceso iniciado oficialmente en 1849 y que continúa vigente hasta el día de hoy- ha procedido de la jurisdicción de Cantón'. Esta provincia a su vez se divide en 21 prefecturas; los nacidos en algunas de ellas al llegar al país se organizaron en Tongs o Huigans (Sociedades), la mayoría ubicadas en el Barrio Chino de Lima, en los alrededores de la llamada Calle Capón². Así podemos apreciar que hoy existen por citar algunas, las sociedades Hok Shan, Cu Con Chau, Tung Sing, Hoi Ping, Nam Joy, Chung Shan, entre otras ${ }^{3}$.

1 广东 (Guângdong), traducido coloquialmente como "expansión al este", provincia ubicada al Sur de China. Llamada así al conformar una dualidad con la provincia vecina de Guângxi (广西, "expansión al Oeste"). Cantón es el nombre castellanizado de su pronunciación en chino. Cabe señalar que en fechas recientes la migración de otras regiones de China también se ha incrementado, específicamente en el caso de la provincia de Fujian. Ver Lausent Herrera (2011) The Chinatown in Peru and the Changing Peruvian Chinese Community (ies) en Journal of Chinese Overseas $\mathrm{N}^{\circ} 7$ Pag. 69-113.

2 Sobre los inicios del Barrio Chino y sus diversas vicisitudes iniciales puede verse el artículo de Humberto Rodríguez Pastor (2004). La Calle Capón, el callejón de Otaiza y el Barrio Chino. En Mundos Interiores, Lima 18501950. Aldo Panfichi y Felipe Portocarrero (editores). Universidad del Pacífico, Perú.

3 Chuhue, Richard y Espinoza, Estela (2012). Una vista al Barrio Chino de Lima. En La Inmigración China al Perú. Arqueología, Historia y Sociedad. Richard Chuhue, Li Jing Na y Antonio Coello (editores) Instituto Confucio de la Universidad Ricardo Palma. Lima - Perú. Páginas 429-450. 
Cantón también es el nombre en español de la capital de la Prefectura (Guăngzhōu, 广州), esta se halla dividida en 10 distritos y 2 ciudades. De ellas, Pun Yui (Pan Yu, 番 禺) es una de las más antiguas y representativas, tanto así que durante la dinastía Qin (秦朝) toda la jurisdicción se conocía con este nombre. Existen muchas teorías acerca del origen
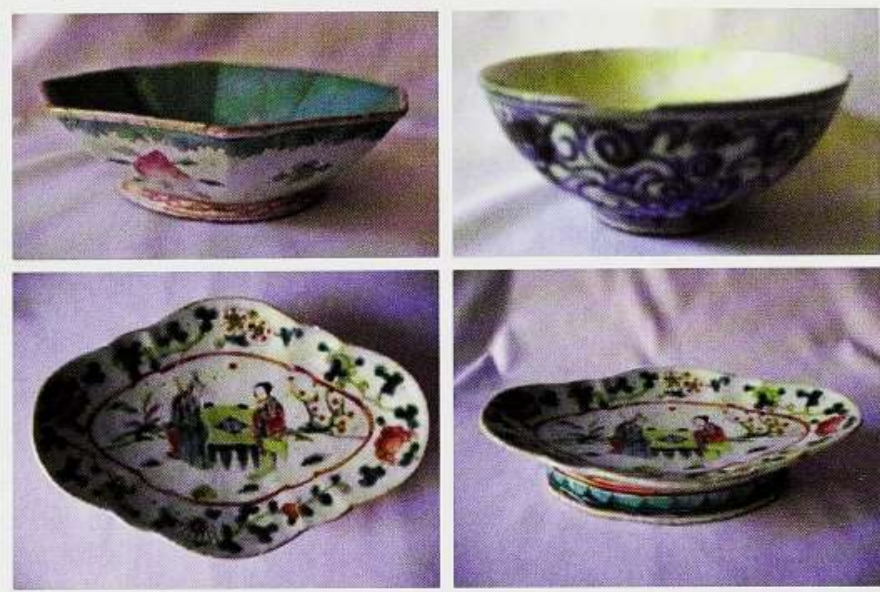

Ejemplos de la diversa loza china. Siglo XIX. de la denominación,

algunos sostienen que se debe a la existencia de dos montañas cercanas conocidas como Pan y Yu. Otros afirman que Pun Yui significa "Puerto del sur", al haber sido esta una comunidad agrícola y dedicada a la pesca ${ }^{4}$. Está situada en el delta del Río Perla (珠江).

\section{Inicios e historia de la Sociedad}

No existe un registro exacto de la fecha de fundación de la Sociedad que agrupa a los nacidos en Pun Yui, debido a que lamentablemente no se conservan documentos ni el registro oficial. Elena Lau, sugiere que este podría estar fechado a fines del siglo XIX, debido a que en los salones del actual local de la Sociedad: “...se guardan celosamente inscripciones con los nombres de los generosos benefactores que con sus donaciones hicieron posible el inicio de este hogar, a partir de la dinastía Qing (清朝), el año 21 del reinado del emperador Guangxu (1895)".

Isabelle Lausent (sin mencionar la fuente que sostiene su afirmación) sitúa el origen un poco antes, señalando que el primer local de esta Sociedad, que estuvo ubicado en la antigua calle Sagastegui ${ }^{6}$, fue adquirido en 1888. La misma autora sugiere que esta Sociedad pudo ser también la "Compañía de Cantón" que se menciona en un documento de 1868 , aunque no existe la certeza de ello.

Existen sin embargo referencias sobre la ubicación del primer local propio de la Sociedad, ubicado en la avenida Abancay, entre los jirones Cusco y Puno, en lo que actualmente es la sede de la Fiscalía del Perú. En los registros de la Municipalidad de Lima para 1905 ya se consignaba como propietarios del predio en la Calle de Abancay № 75 a una Sociedad de Beneficencia China que aportaba $\mathrm{S} / .14 .40$ soles de contribución anual por concepto de una

4 Sociedad Pun Yui Wui Kun en Revista Oriental N 806-7, año LXVIII, Julio-Agosto 1999.

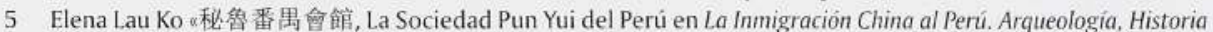
y Sociedad. Richard Chuhue, Li Jing Na y Antonio Coello (editores) Instituto Confucio de la Universidad Ricardo Palma. Lima - Perú. Página 308-309.

6 Actual cuadra 6 de la avenida Abancay. Véase Juan Bromley. Las Viejas Calles de Lima. [1960] 2007. Página 284. Edición virtual de la Biblioteca y Archivo Historico Municipal de Lima. http:/www.munlima.gob.pe/biblioteca/ biblioteca_municipal_archivo historico/biblioteca_municipal_virtual/biblioteca_municipal_virtual.htm. Recuperado el [18 de julio de 2013 ].

7 Isabelle Lausent-Herrera. Sociedades y templos chinos en el Perú. Fondo Editorial del Congreso de la República del Perú, 2000. Página 139. 
tienda pública ubicada en sus pisos inferiores. Unos años después, en 1914, el mismo local ya signado con una nueva numeración (Abancay $N^{\circ} 627$ y N633) aportaba casi S/.90.00 soles de contribución anual por ambas tiendas. ${ }^{8}$ Esta amplia sede contaba con habitaciones para el alojamiento de los "paisanos" que recién llegaban al país, además de Salón Principal, sala de reuniones y entretenimiento, cocina y también, como ya hemos visto, locales comerciales anexos que se alquilaban para solventar los gastos de la institución. En 1946 este lugar fue demolido por la Municipalidad de Lima, que expropió el lugar para la ampliación de la avenida Abancay. De esta forma la directiva decide mudarse a otra ubicación, siempre en las cercanías del Barrio Chino, eligiéndose la propiedad situada en el Jirón Paruro No1129 como nueva sede institucional. Esta ubicación, de $780 \mathrm{~m}^{2}$, se inauguró el 29 de julio de $1949 .{ }^{9}$

\section{Registro y catalogación del patrimonio mueble}

El local de la Sociedad Pun Yui ubicado en Jr. Paruro habia ido perdiendo con los años el activismo y brío que tuvo en décadas anteriores, donde las festividades chinas, bodas, velorios y cotidianas reuniones alimentaban la vida de la Sociedad y sus integrantes. Aproximadamente desde hacía unos 20 años atrás que parte de sus ambientes y mobiliario no se utilizaban, confinándolos al olvido y deterioro en las húmedas habitaciones o en la azotea del local.

En el año 2009, con motivo del 50 aniversario de la edificación de la nueva sede, la directiva de la Sociedad impulsó un proyecto de remodelación del local que incluyeron el rescate y preservación de lo que quedaba del amplio patrimonio mueble que tuvo la sociedad en sus inicios, el cual incluía muebles tradicionales chinos de ébano, gran cantidad de loza china y menaje de mesa, utensilios de cocina, jarrones decorativos de porcelana, cuadros, adornos variados, un finisimo y singular adorno colgante hecho de madera y cartón y el espectacular altar de madera tallada donde se encuentra la venerada figura de Guang Kong ${ }^{10} \mathrm{con}$ todos sus muebles y elementos de culto asociados.

8 Archivo Histórico Municipal de Lima. Sección de Contribuciones. Junta Departamental de Lima - Predios Urbanos. Tomo I, 1903-1907. página 17. Tomo I, 1913-1917. Páginas 9 vuelta y 10.

9 Ibid nota 5.

10 El culto a Guang Kong es uno de los más difundidos en la comunidad china en el Perú y es característico del sur de China. También se le conoce, entre otras formas, como Guan Yu, Kwang Tai-Kung, Guangong, etc. En la vida real se trató de un guerrero y burócrata de la dinastía Han, deidificado y respetado tanto en las creencias budista, taoista y el confucionismo como protector del hogar, el comercio y la justicia. En el Perú la influencia de la inmigración china hizo que también fuera incorporado en el santoral católico y que la población peruana a partir del siglo XIX lo identificara como San Acon. Véase Marticorena. Miguel. Procesión de Confucio y Acón en Lima en Historia de Lima. Miguel Marticorena, Richard Chuhue (et. al). Centro Cultural de la Universidad Nacional Mayor de San Marcos. Lima-Perú. 2011. Páginas 205-206. 

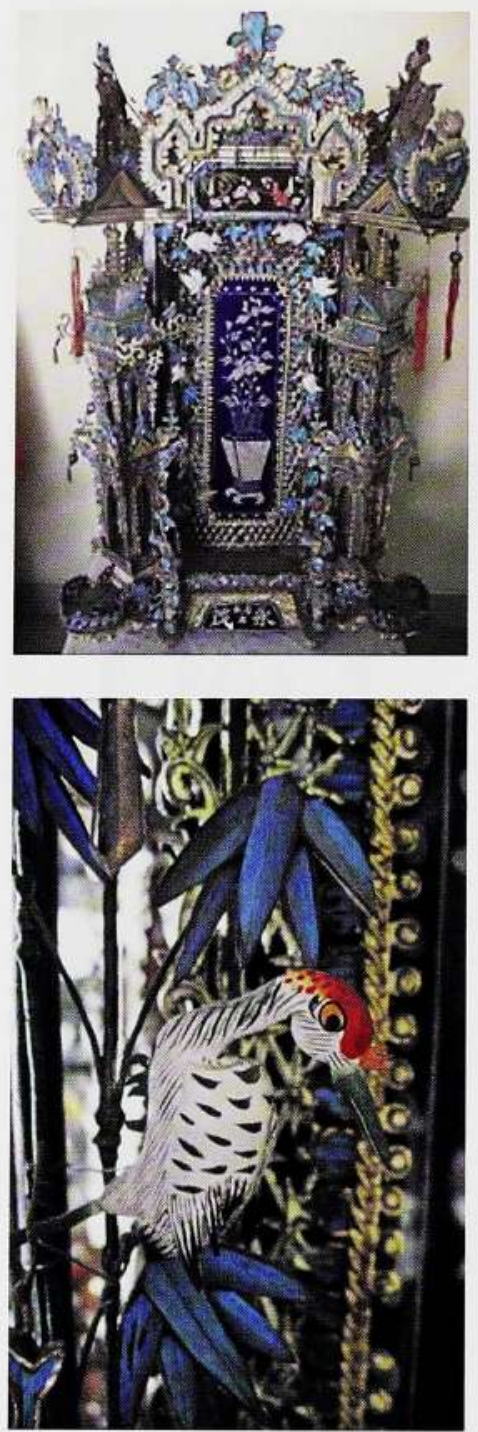

Adorno colgante elaborado de madera con aplicaciones de cartón pintado y dorado. Las partes de color turquesa corresponden a aplicaciones de plumas. Posiblemente haya sido un candelabro que se intuye por las piezas faltantes.

Además de lo numerado anteriormente se conservaba gran cantidad de documentos y manuscritos en los cuales se registra la vida y actividades de la Sociedad. Una colección de fotografías de la época de edificación del local da cuenta gráficamente de las instalaciones originales, así como las actividades sociales que allí se realizaban y algunos miembros ilustres. Todos estos materiales se encontraban dentro de un mueble, enrollados, en paquetes y bolsas.

La directiva de la Sociedad definió como objetivos principales para el proyecto:

- Inventariar e identificar todos los bienes de la Sociedad.

- Clasificación y preservación de la documentación histórica existente.

- Planificar acciones para el mantenimiento de las piezas de la colección.

- Exhibir parte de su patrimonio histórico a sus miembros y a la sociedad en general.

Con la guía de estos objetivos se tomaron acciones inmediatas que se realizaron con apoyo de profesionales arqueólogos y técnicos:

- Registro y catalogación de todo los bienes muebles de la Sociedad.

- Ordenamiento y conservación del patrimonio documental y fotográfico.

- Limpieza de todas las piezas, incluyendo la restauración de gran parte de ellas.

- Seleccionar y crear los medios museográficos para la exhibición de las piezas.

El desarrollo del proyecto tomó cerca de cuatro meses, teniendo tres etapas de trabajo: primero el equipo se avocó a la tarea de registrar, enumerar y describir las piezas y luego se procedió a la limpieza de todo el material y la restauración de las que necesitaban este tratamiento. Finalmente se acondicionó, preparó y montó las vitrinas de exhibición.

\section{Recursos y ambientación}

El principio a tomar en cuenta al momento de definir los recursos museográficos para exhibir parte del patrimonio de la Sociedad fue respetar la arquitectura y distribución del mobiliario ya existente. Cuando la directiva asignó la tarea de considerar una exhibición museográfica en sus instalaciones ya muchos ambientes estaban distribuidos. En el segundo nivel del predio, que es donde se ubica la muestra, existian ya un salón de reuniones, oficinas, el altar a Guang Kong (que cuenta además con una fina escultura de la barca de los inmortales del siglo XIX), un salón para honrar y venerar a los difuntos miembros de la Sociedad y una cafetería. Los espacios apropiados y disponibles para la exhibición estaban muy restringidos, con lo cual solamente se podían utilizar los ambientes que brindaban 
dos salones y un corredor. Se determinó por ello la utilización de tres vitrinas, cada una con un tema de exposición.

El diseño se realizó sin la posibilidad de realizar trabajos de mayor intervención tales como hacer sistemas de iluminación especial y acorde con los materiales, cambiar partes de la arquitectura o la decoración del lugar, debido a los lineamientos dados por la Directiva y por tratarse de un edificio histórico.

\section{Pautas museográficas de la exposición}

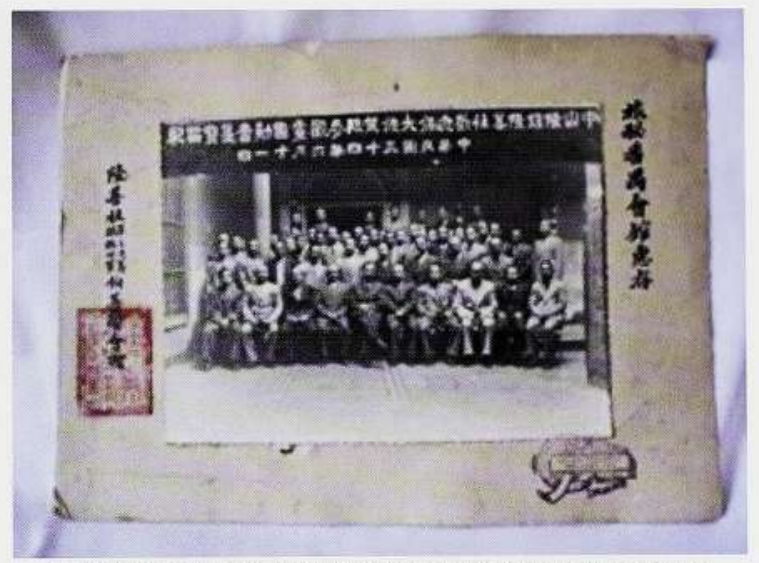

Parte de las fotografias que conserva la Sociedad. La imagen es de una reunión de miembros de la colonia china.

Se definieron dos grandes grupos de elementos a exponer: los objetos que muestren las actividades que la Sociedad desarrollaba en el local, principalmente celebraciones relacionadas a las fiestas tradicionales chinas (año nuevo, fiesta de la luna, etc.), en donde el eje central eran los grandes banquetes. Los objetos relacionados a estos eventos son la gran cantidad y diversa loza que se ha conservado (tazas para arroz, cuencos, platos, palillos de madera, cucharas, etc.) y utensilios para la preparación de dichos festines: wok, cucharones, machetes, etc. Muchos de estos objetos provienen de finales del siglo XIX, desde los inicios de la Sociedad, importados desde China exclusivamente para estos fines. ${ }^{11}$

El otro grupo fue el patrimonio documental, conservándose documentos que narran las actividades que la Sociedad desarrollaba tales como anuncios en periódicos, actas de reuniones y votaciones de las directivas, libros de registro de miembros, algunas actas de defunción de algunos miembros socorridos por la Sociedad, etc. Ambos grupos fueron exhibidos en vitrinas propias, en donde cada pieza o grupo de piezas están referidos con leyendas o explicaciones.

Una tercera vitrina pequeña se reservó exclusivamente para el adorno colgante hecho de madera y cartón con aplicaciones de plumas, debido a lo singular de su belleza y manufactura. Es una

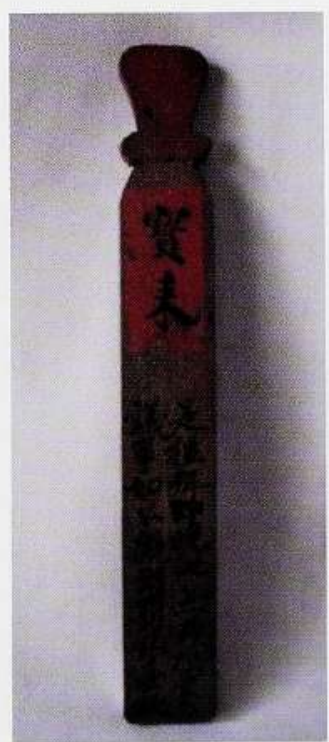

Tablilla usada por los miembros de la Sociedad para asistir a las reuniones y ejercer su voto. reliquia sin igual que se ha podido conservar casi totalmente.

Lo que se ha querido transmitir al público a través de la exhibición es la vida esplendorosa que tuvo la Asociación en sus épocas de apogeo, situación que nuevamente la Directiva actual desea relanzar, ya no únicamente enfocada a sus miembros directos, sino además

11 Referencialmente podemos acotar que la importación de elementos de manufactura china es de muy antigua data en el Perú, habiéndose encontrado piezas que provienen de incluso de inicios de la presencia hispana en el Perú. Véase Mogrovejo, Juan Informe sobre cerámica china, siglo XVI en Herederos del Dragon. Historia de la comunidad china en el Peru. Humberto Rodríguez Pastor. Lima, Fondo editorial del Congreso de la Republica. 2000. Páginas $477-478$. 

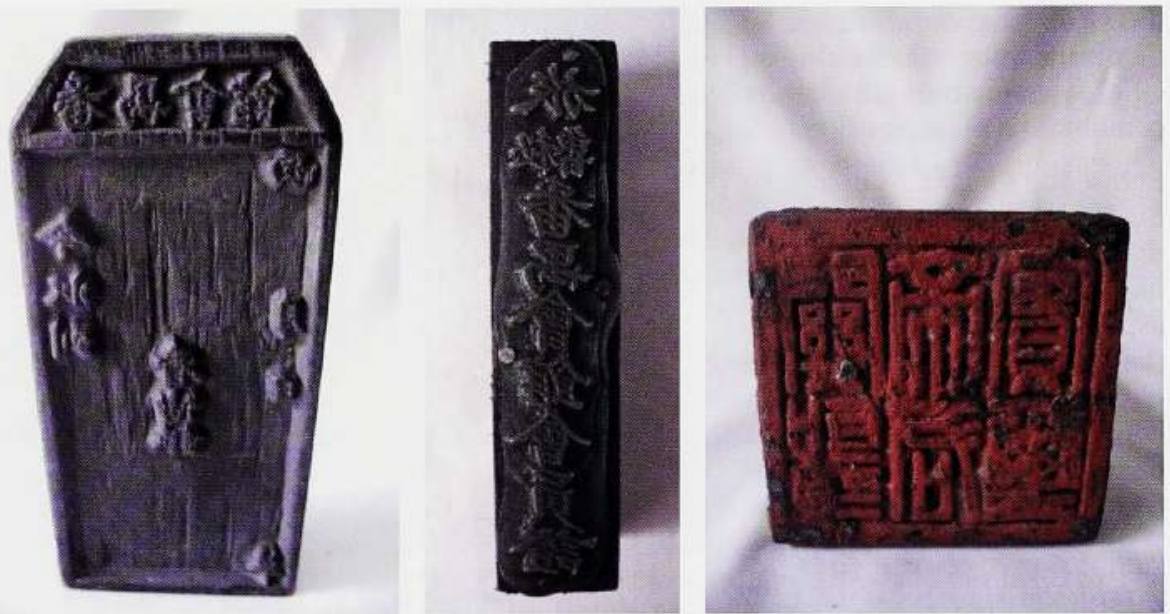

Diversos tipos de sellos utilizados para diferentes actividades

dar la proyección hacia la comunidad peruana para que conozcan la Sociedad Pun Yui en particular y entiendan de manera general cómo era el funcionamiento, organización y la vida de las sociedades chinas en el Perú.

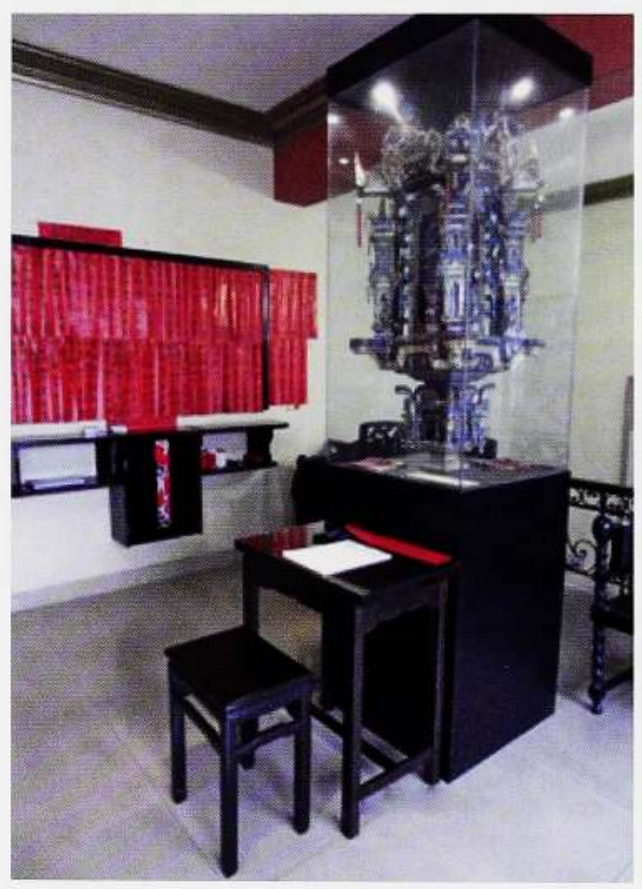

Vitrina donde se exhibe el adorno colgante, una de las piezas artísticas más importantes de toda la colección. Al fondo se pueden apreciar también las inscripciones en han zi de los nombres de los benefactores y donantes para la manutención del local.

\section{Repercusión y futuro}

Con la recuperación de su local y el rescate de su patrimonio cultural mueble, lo que la Sociedad Pun Yui persigue es un fin de trascendencia: lograr que a través de los objetos y las actividades que ahora desarrollen las futuras generaciones de chinos e hijos de chinos en el Perú ("tusán") reconozcan sus raíces, lo acepten y lo asuman como parte de su identidad como grupo.

A lo largo de los años, la comunidad china ha ido siendo testigo y partícipe de muchas de las quiebras y desapariciones de las antiguas sociedades chinas debido a factores que ya varios autores han tratado. Existe una inquietud, un deseo de una parte de los tusán por rescatar y revalorar este patrimonio cultural de su propia comunidad, que poco a poco va a ser posible canalizar a través de acciones concretas y directas que lleven a resultados de gran satisfacción como la Sociedad Pun Yui.

Es de destacar esta iniciativa tomada por la Sociedad Pun Yui para habilitar áreas de exhibición en sus instalaciones 
y su deseo de que se convierta en un espacio permanente de difusión de sus actividades e historia, debido a que la percepción de la población peruana acerca de las sociedades tradicionales chinas es la de espacios cerrados no abiertos al público en general. En ese sentido, el Barrio Chino de Lima carece de instalaciones museográficas en su entorno (como si las tienen los Chinatowns de ciudades como Nueva York o California, por citar solo dos ejemplos) en las que los turistas e interesados puedan interactuar y conocer más de cerca el proceso de integración de la colonia china con el país. Con esta decisión y el empeño que la directiva actual tiene, se pueden habilitar en el futuro recorridos turísticos en la zona, que incluyan visitas guiadas a su museo, lo cual nos permitirá tener avances considerables al respecto.

Además, existe la intención de inscribir las piezas más importantes de la Sociedad al registro del patrimonio mueble del Ministerio de Cultura en aras de la protección de los mismos.

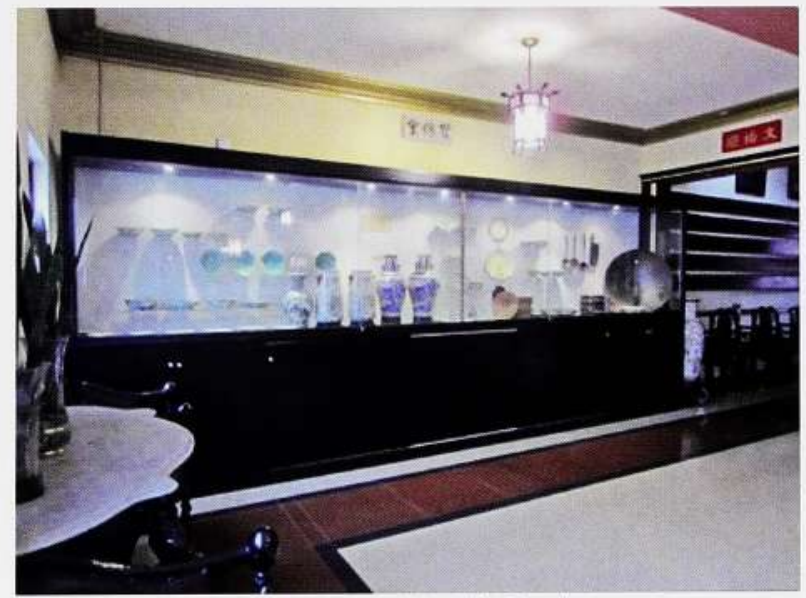

Vitrina donde se exhibe parte de la vajilla, finos jarrones y otros objetos que representan la vida de la Sociedad.

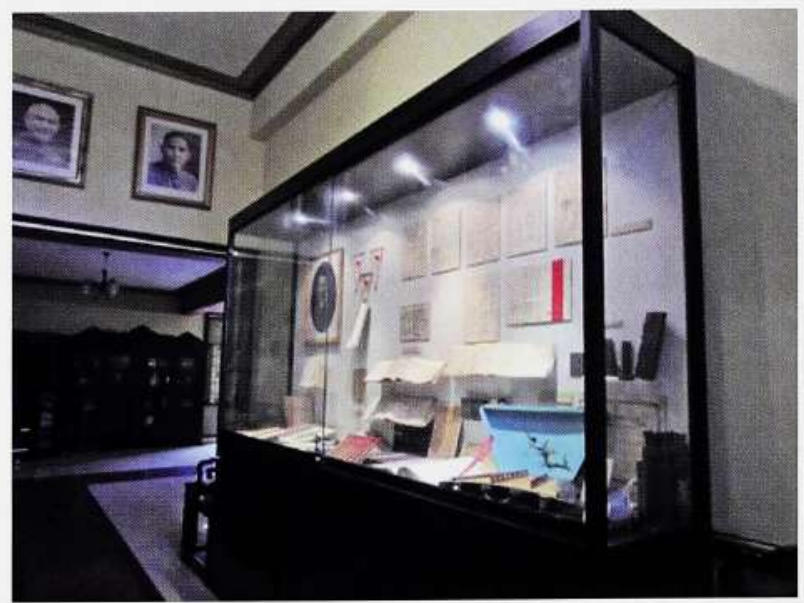

Vitrina donde se exhibe el patrimonio documental que es una génesis de la vida de los paisanos Pun Yui en el Perú.

Este mismo trabajo emprendido en la Sociedad Pun Yui se desea replicar con otra sociedad importante para la colonia china como es la Sociedad Tung Sing, ubicado en la cuadra 9 del Jirón Huanta en el Cercado de Lima (popularmente conocida como "Oráculo Chino"). El local de esta sociedad es una de los más antiguos que se conserva en Lima ${ }^{12}$ y por sus singulares características y estado de conservación urge una intervención profesional.

12 El templo, ubicado en el segundo nivel, es el más antiguo de Sudamérica. Para ver una descripción de la lectura taoista del I-Ching que realizaba hasta hace unos años en el local el Sr. German Koo véase: Revista Andares. Diario La República. Año II, No 93. Octubre de 1999: Operación Dragón: de vuelta al Barrio Chino. Pág. 7. 